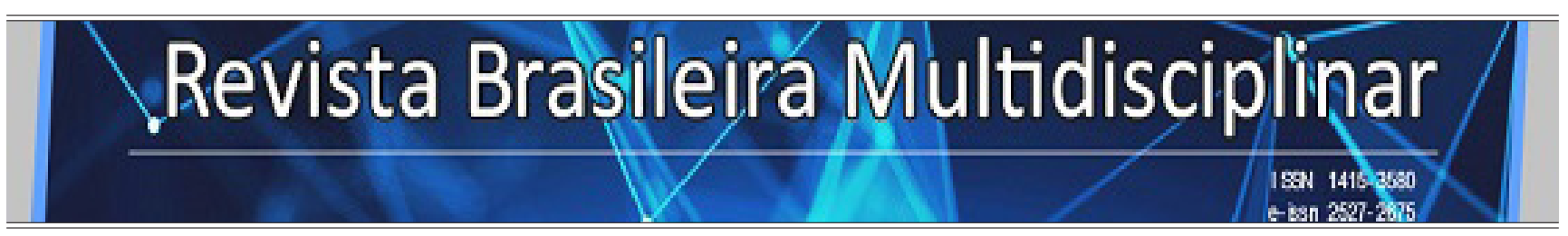

http://revistarebram.com/index.php/revistauniara

\title{
IMUNOTERAPIA COMO NOVA PESPECTIVA NO TRATAMENTO DE HIPERSENSIBILIDADE TIPO 1 NAS VIAS AÉREAS
}

Juliana da Silva Oliveira Faccio*; Vinícius Silva Pereira**; Samanta Romão Correa**; Hadassa da Silva Sanches Garcia ${ }^{* *}$; Sthepheny Gaion Ciccoti**; Rafael Bessi Constantino*; Andrezza Furquim da Cruz ${ }^{* *}$.

${ }^{*}$ Docente da Universidade de Araraquara - UNIARA. Pesquisadora na área de imunologia clínica, alergia e doenças auto-imunes.

${ }_{* *}^{*}$ Universidade de Araraquara.

*Autor para correspondência e-mail: jofaccio@uniara.edu.br

\section{Palavras-chave}

Hipersensibilidade

Imunoterapia

Rinite Alérgica

Asma

\section{KEYWORDS}

Hypersensitivity Immunotherapy Allergic Rhinitis Asthma

\section{Resumo}

A alergia ou Hipersensibilidade imediata ou do tipo I, é uma patologia de ocorrência mundial, diretamente ligada à genética, podendo acometer diversos órgãos e tecidos, sendo as mais frequentes na população a rinite e a asma. Esses dois tipos de alergias causam prejuízo na qualidade de vida podendo, em algumas situações, levar a problemas respiratórios fatais. Ao longo dos anos, essas alergias têm sido tratadas com anti-histamínicos e corticoides, porém ambos não trazem resultados definitivos e duradouros. A imunoterapia alérgeno-específica (AIT) tem sido usada como potente indutor de tolerância imunologica, melhorando ao longo de anos, a qualidade de vida de pacientes portadores de alergias respiratórias e prevenindo o avanço da rinite alérgica (RA). Assim, o presente estudo tem por objetivo revisar os mecanismos da Hipersensibilidade tipo 1, bem como, a eficácia, benefícios clínicos e segurança, e o processo de atuação imunológica da recém-descoberta imunoterapia sublingual (SLIT), comparados à subcutânea (SCIT) na asma e RA. Para tanto, foram utilizados como base artigos publicados entre 2005 e 2018, disponíveis no banco de dados PubMed e Scielo, assim como livros e revistas de Imunologia. Essa pesquisa permitiu concluir que a AIT é capaz de alterar o curso natural da doença, impedindo a progressão da RA e prevenindo a asma. Apesar de ainda haver controvérsias sobre os métodos de administração, a terapia por SLIT tem se mostrado mais vantajosa que a SCIT devido à facilidade de adesão ao tratamento, aumentando assim, a qualidade de vida dos pacientes..

\section{IMMUNOTHERAPY AS A NEW PERSPECTIVE IN THE TREATMENT OF AIRWAYS TYPE 1 HYPERSENSITIVITY}

Allergy or type I Hypersensitivity is a worldwide pathology, linked to genetics, which affects several tissues and organs, and the most frequent in the population is rhinitis and asthma. These two kinds of allergies cause loss of life quality leading to fatal respiratory problems in some situations. Over the years, these allergies have been treated with antihistamines and corticosteroids, but they do not bring definite and longstanding results. Allergen-specific immunotherapy (AIT) has been used as a powerful inductor of immune tolerance, improving the life quality of patients with respiratory allergies, and preventing the advancement of allergic rhinitis (RA) over the years. The aim of the present study was to review the mechanisms of Type 1 Hypersensitivity, as well as the efficacy, clinical benefits and safety, and the immunological performance of the newly discovered sublingual immunotherapy (SLIT), compared to subcutaneous (SCIT) and pharmacotherapy for allergies in asthma and RA. For this, were searched articles published between 2005 and 2018 available in PubMed and Scielo databases, as well as in books and journals of Immunology. This work shows that the AIT is able to alter the natural course of the disease, preventing asthma and the RA progression. Although there are still discussions about the methods of administration, SLIT therapy has shown to be more advantageous than SCIT because of the easiness to follow the treatment, increasing patient's life quality. 
Faccio et al.

\section{INTRODUÇÃo}

A reação de hipersensibilidade do tipo I é iniciada por imunoglobulinas tipo E (IgE) e mastócitos, o qual possui componentes inflamatórios dentro de seus grânulos que irão causar efeitos fisiológicos no organismo. Depende da sensibilização do indivíduo por algum antígeno denominado alérgeno, produzindo uma gama de mediadores inflamatórios, tais como histamina, eicosanoides, quimiocinas, citocinas e espécies reativas de oxigênio (EROS), desencadeando respostas imunológicas que variam de acordo com o tipo que sensibilizou a pessoa (THANGAM et al., 2018)

Doenças alérgicas respiratórias, como a rinite e a asma, são um problema de saúde mundial sendo a doença crônica mais frequente na Europa e nas sociedades ocidentais que atinge tanto crianças como adultos, tornando-se extremamente prejudiciais na vida dessas pessoas, uma vez que altera a rotina diária dos enfermos, fazendo-os dependentes da farmacoterapia, que nem sempre é efetiva nesses casos. Dentre os pacientes que apresentam rinite alérgica intermitente, 79,2\% apresentam algum comprometimento de sua vida profissional e $91,8 \%$ de sua vida diária (KIOTSERIDIS et al., 2018).

Anti-histamínicos e costicosteroides nasais são eficazes no tratamento com farmacoterapia, utilizados para reduzir os sintomas da alergia, mas não previnem a progressão da doença, além de causar efeitos colaterias anticolinérgicos, antidopaminergicos, antisserotoninérgicos e alterações no ciclo do sono e vigília, prejudicando a qualidade de vida dos portadores com sintomas de sedação, exaustão, sonolência e perda na concentração de atividades do dia a dia (KIOTSERIDIS et al., 2018; PASTORINO, 2010). Além disso, a associação de corticosteroides intranasais à esteroides administrados por outras vias, podem levar a supressão do eixo hipotálamo-hipófise-adrenal, podendo por exemplo, provocar retardo no crescimento estrutural em crianças (IBIAPINA et al., 2008).

A imunoterapia com alérgenos (AIT) nas suas mais diversas formas de administração surgem com o intuito de criar uma tolerância imunológica, causando modificação na resposta a alérgenos específicos e alteração no curso natural das doenças alérgicas respiratórias, diminuindo de maneira acentuada os sintomas, melhorando a qualidade de vida do indivíduo, e impedindo a progressão da doença. (ZHANG et al., 2017; PFAAR et al., 2017). Portanto, a AIT se torna de extrema importância por representar a principal abordagem preventiva para os principais acometimentos de hipersensibilidade do tipo 1 nas vias aéreas.

Desta forma, esta revisão bibliográfica visa demonstrar a eficácia, importância e mecanismos de ação imunológica da imunoterapia alérgeno-específica (AIT), bem como comparar as principais estratégias de administração no tratamento da hipersensibilidade tipo 1 em doenças respiratórias tais como asma e rinite alérgica, demonstrando estudos mais recentes sobre a AIT.

\section{Metodologia}

Este artigo é uma Revisão Bibliográfica que teve como base de busca informações em artigos online, publicados nas plataformas Scielo e PubMed, em Inglês, Espanhol e Português, de 2005 a 2018, assim como livros e revistas de Imunologia Básica. As palavras utilizadas para buscas foram: Imunoterapia sublingual/subcutânea, hipersensibilidade do tipo 1, rinite alérgica, asma e alergias relacionada a vias aéreas, bem como suas devidas traduções para os idiomas supracitados.

\section{RESULTADOS E DISCUSSÃo}

\section{HIPERSENSIBILIDAdE do TIPO 1 E AS VIAS AÉREAS}

A doença alérgica das vias aéreas afeta o revestimento da mucosa e pode abranger do nariz até os pulmões, com uma variedade de sintomas baseados no local de acometimento. Os tratos respiratórios superior e inferior compartilham semelhantes características anatômicas, funcionais, patogênicas, clínicas e imunológicas, com a inclusão da mesma rede mole, reagindo aos alérgenos transportados pelo ar através da ativação de células efetoras semelhantes (MORJARIA et al., 2018). 
A asma é uma doença respiratória crônica caracterizada por uma inflamação das vias aéreas inferiores, causadora de recorrente falta de ar, sensação de aperto no peito, episódios de tosse noturnos ou no início da manhã, hiper-reatividade brônquica e obstrução do fluxo aéreo. A asma alérgica, mediada por Th2 (linfócito T auxiliar 2) e IgE, tem início precoce e forte histórico familiar, ou seja, surge logo na infância em pacientes já acometidos por outras doenças como RA. Essas patologias apresentam excessiva liberação de secreção e muco, bem como bronco-constrição causadas pelos mediadores liberados pelos mastócitos (RICE, 2018; KUMAR; BHATIA, 2013).

A rinite alérgica (RA) pode predizer a progressão para asma tanto em crianças como em adultos. Morjaria et al. (2018) relataram que em estudo prospectivo recente, crianças com RA persistente moderada a grave desenvolveram asma de início recente aos 5 anos de seguimento, e, segundo eles, o desenvolvimento de asma foi observado em um terço das crianças com RA leve, reforçando a relação entre progressão da RA para a asma. Os autores afirmaram, ainda, forte relação entre as doenças nasais alérgicas e asma, com uma prevalência que pode chegar a $80 \%$, podendo ser explicado pela presença de inflamação nasal persistente que está associada ao acometimento das vias aéreas inferiores com infiltração da mucosa e comprometimento da função pulmonar. Outro fator citado pelos mesmos é que o avanço da RA para a asma pode ser devido à exposição repetida à antígenos altamente alergênicos inalados, como por exemplo, o ácaro da poeira doméstica (HDM), usualmente implicado no desenvolvimento da asma.

Kumar e Bhatia (2013) relataram que os ácaros são os principais responsáveis pela alta prevalência de hipersensibilidade do tipo 1 na asma, provocando a ativação de células TH2, que induz a produção de IgE específica e o recrutamento de células inflamatórias que causarão alterações estruturais no pulmão nessa doença. Um estudo realizado por Ferreira (2015) em Portugal, reporta os ácaros, principalmente a espécie Dermatophagoides pteronyssinus presente no pó doméstico, como um fator de risco e causa mais frequente para o desenvolvimento de doenças respiratórias como a asma e a rinite alérgica (RA).

A prevalência da RA está aumentando globalmente, afetando de 10 a $40 \%$ da população mundial, e geralmente, se sobrepõe à asma em níveis de incidência. A RA causa prurido, espirros, rinorréia e cólon nasal, podendo estar associada à sintomas oculares, prurido de palato, gotejamento pós-nasal e tosse. Quando associada à asma, acomete entre 15 e $38 \%$ dos pacientes, sendo que dos $85 \%$ dos pacientes que possuem asma, somente $6 \%$ apresentam sintomas nasais. Esse fato mostra que a RA é um importante fator de risco para o início da asma, e, se apresentada na forma moderada ou grave não controlada, pode afetar de forma significativa o controle da asma. Logo, tem-se investido na imunoterapia específica com alérgenos (AIT), atualmente administrada para o tratamento de asma alérgica em combinação com outros fármacos como forma de prevenção, a fim de reduzir os riscos de início dessa doença (ELENIUS; JARTTI, 2016; ZHANG et al., 2017; MORJARIA et al, 2018).

\section{IMUNOTERAPIA COM ALÉRgENO (AIT)}

Anti-histamínicos, costicosteroides nasais ou antagonistas dos receptores de leucotrienos são eficazes no tratamento com farmacoterapia, utilizados para reduzir os sintomas da alergia, mas não previnem a progressão da doença. Os anti-histamínicos surgiram há 70 anos na tentativa de minimizar os sintomas da alergia. Esse tipo de fármaco tem a capacidade de transpor a barreira hematoencefálica podendo gerar efeitos colaterais anticolinérgicos, antidopaminérgicos, antisserotoninérgicos e alterações no ciclo sono e vigília que prejudicam a qualidade de vida dos portadores com sintomas de sedação, exaustão, sonolência e perda na concentração em atividades do dia a dia (KIOTSERIDIS et al., 2018; PASTORINO, 2010). Pacientes que fazem o uso prolongado de corticosteroides intranasais associados a esteroides administrados por outras vias, são mais propensos a apresentar supressão do eixo hipotálamo-hipofiseadrenal, sendo que, em crianças, este fato pode provocar retardo no crescimento estatural (IBIAPINA et al, 2008; SOHN, 2018) 
A imunoterapia com alérgeno (AIT), em contraste à farmacoterapia convencional, envolve a administração de alérgenos específicos e surgiu com o intuito de induzir a tolerância imunológica por modificar a resposta a alérgenos específicos, dessa forma, alterando o curso natural das doenças. Sendo assim, a AIT tem por finalidade produzir uma melhora na qualidade de vida dos indivíduos com asma, prevenir a progressão da rinite alérgica, além de prevenir a progresso da alergia em crianças e prevenir sensibilização de bebês nas alergias aos ácaros (ZHANG et al., 2017; PFAAR et al., 2017; SOHN, 2018).

O primeiro relatório do uso de AIT remonta a 1911, quando Leonard Noon obteve melhora sintomatológica por quase 1 ano após injear extrato de pólen de grama em indivíduos alérgicos. Desde então, houve um progresso significativo no campo de caracterização de alérgenos e compreensão de vias que impulsionam a tolerância imunológica (SATISTSUKSANOA et al., 2018).

\section{MECANismo de AÇÃo dA AIT}

AIT pode ser administrado por via subcutânea (SCIT) ou sublingual (SLIT). A imunoterapia subcutânea (SCIT) foi desenvolvida e tem sua eficácia comprovada por mais de 100 anos, enquanto uma nova forma de administração, a imunoterapia sublingual (SLIT) foi lançada na última década e introduzida como uma terapia alternativa (ABOSHADY; ELGHANAM, 2013; KIOTSERIDIS et al., 2018).

As duas formas de AIT envolvem dispositivos de ação semelhantes, sendo que, ambos os tipos de imunoterapia atuam nas mesmas células: mastócitos, basófilos, eosinófilos, células dendríticas, células T e células B. Em relação as três primeiras células apresentadas, descobriu-se uma diminuição no recrutamento dentro do local da inflamação após o uso da AIT. Já as células dendríticas podem ser importantes, uma vez que se observou que a imunoterapia bem-sucedida promove o efeito antialérgico dessas células. A participação das células T, por sua vez, ocorre através da deleção de células Th2 específicas de alérgenos e alteração, de maneira favorável, do equilíbrio entre as células Th2 e Th1/Tr1 (VIRTANEN, 2017).

O LTh (linfócito T auxiliar) é uma célula de extrema importância no desenvolvimento das alergias, visto que é ela quem libera citocinas para que os anticorpos do tipo E sejam produzidos. Em indivíduos alérgicos, existe uma atopia genética que leva o indivíduo a produzir IgE. Para que a produção de IgE seja estimulada pelo LTh é necessário que ele se torne padrão Th2, e isso depende totalmente do tipo de antígeno e da atopia genética do indivíduo, no qual o predomínio de Th2 passa a liberar principalmente interleucina 4 (IL-4) responsável pela produção de IgE e de IL-5 responsável pela ativação dos eosinófilos. Esse LTh inicialmente é conhecido como TH0 (linfócito T auxiliar 0) pode se diferenciar para Th1 (linfócito T auxiliar 1) ou Th2 dependendo tanto da natureza do antígeno quanto das citocinas presentes, sendo que vale destacar que um padrão é capaz de inibir o outro. Por muitos anos foi considerado que a imunoterapia em indivíduos alérgicos conduzia um desvio do padrão Th2 para o Th1, pois causava uma diminuição dos níveis das interleucinas IL-4, IL-5 e IL-13, e aumento de interferon gama (IFN- $\gamma$ ), o que gerava inversão do predomínio da subpopulação de Th2 para Th1, causando inibição da resposta alérgica (PEREIRA; AUN; MELLO, 2017).

Recentemente foi estudado que a conquista da AIT não depende exclusivamente do desvio do padrão Th2 para Th1, mas também de um mecanismo de tolerância dependente de células T regulatórias (Treg) e células B regulatórias (Breg) que propiciam alterações nos pacientes que fazem uso desse tipo de tratamento. As modificações encontradas nos indivíduos classificam-se em precoces, intermediárias e tardias (PEREIRA; AUN; MELLO, 2017).

A primeira classificação é apresentada como alteração precoce, onde, em algumas horas, mesmo com níveis aumentados de IgE, há uma diminuição na ativação e degranulação de mastócitos e basófilos. No início do tratamento os níveis de IgE específicas ainda estão elevados, contudo, meses após o início do procedimento é possível observar uma queda gradual nos níveis dessa imunoglobulina (HANCI et al., 2015). 
Os mecanismos moleculares que explicam a diminuição da degranulação dessas células mesmo na presença de níveis evidentes de IgE específica são explicados por Berings et al. (2017). Os autores descrevem um mecanismo que envolve receptores para alguns subtipos de imunoglobulinas G (CD32) e receptores de manose ambos dos basófilos. Para eles, IgG2 (imunoglobulina G do tipo 2) e IgG3 (imunoglobulina G do tipo 3) recrutam o CD32 e tem efeito na inibição de receptores FcERI em basófilos humanos, além disso, um alérgeno pode se ligar a receptores de manose acoplados a manano não oxidado sem a necessidade de IgE. Sendo assim, ambos os receptores participam da inibição da degranulação na alteração inicial da AIT.

Existem hipóteses que talvez a administração de doses crescentes de alérgenos na fase inicial da AIT, possa estar induzindo a exaustão dos mediadores de células efetoras. Essa administração precoce é conhecida como processo de dessensibilização. O efeito de dessensibilização da AIT ocorre devido à rápida regulação positiva dos receptores de histamina. Embora este processo, sofrido por basófilos e mastócitos, mesmo na presença de IgEs específicas, não estar claramente desvendado, sabe-se que em poucas horas após o início do procedimento, há um aumento dos receptores de histamina tipo 2 (H2), que promove uma cascata biomolecular de eventos que levam ao aumento intracelular de monofosfato cíclico de adenosina (AMPc) o qual inibe a ativação de receptores FcERI por ligação cruzada, reprimindo a degranulação de mastócitos e basófilos (VEEN et al., 2017). Quando precoce, a dessensibilização pode ser mediada pela regulação positiva do receptor de histamina 2 (H2) que inibe a ativação induzida por cross-linking Fc冈RI e liberação mediadora de basófilos. Estes receptores são expressos em maior quantidade em pacientes que fizeram imunoterapia e o aumento desses receptores estão relacionados com uma diminuição da liberação de mediadores pelos mastócitos e basófilos, este receptor pode ser considerado tolerogênico (SATITSUKSANOA et al., 2018).

Por outro lado, os receptores de histamina do tipo 1 (H1) ativam células Th1 favorecendo o processo de inflamação. A associação da histamina com o receptor $\mathrm{H} 2$ reduz a capacidade de apresentação de antígeno, causando aumento da produção de IL-10 que por sua vez, aumenta a capacidade de supressão das células Treg (PEREIRA; AUN; MELLO, 2017).

As mudanças do tipo intermediárias envolvem transformações nas células T. As células Treg orquestram a resposta imune causada pela alergia através da supressão de fatores pró inflamatórios e também por meio de IL-10 e do fator de transformação do crescimento beta (TGF- $\beta$ ) que inibem células dendríticas responsáveis pela diferenciação de Th1 e Th2. Nesta fase é possível observar uma diminuição dos fatores quimiotáticos para eosinófilos e neutrófilos, e queda na atividade dos eosinófilos (CHIRUMBOLO et al., 2017).

A fase tardia da AIT engloba as células B regulatórias (Breg) do tipo Br1. A IL-10 e o TGF- $\beta$ secretados pelas células Treg e Breg estimulam as células B a sofrerem mudança de classe, suprimindo IgE específica e induzir a produção dos anticorpos protetores IgG4 (imunoglobulina G do tipo 4) e IgA2 (imunoglobulina A do tipo 2) na presença de IL-4, enquanto que a IL-4 sozinha induziria IgE. A IgG4 é vista como um anticorpo bloqueador capaz de concorrer com a IgE pelos locais de inserção com o antígeno, dessa forma, é relevante para evitar o mecanismo de degranulação de basófilos e mastócitos (PEREIRA; AUN; MELLO, 2017).

O diferencial do mecanismo de interação da SLIT é que este depende da interação com células da cavidade oral, no qual, primeiramente, os produtos são administrados sob a língua e são mantidos ali por alguns minutos até serem engolidos. Após a interação uma quantidade substancial de alérgenos adere às células epiteliais em alguns minutos até que são absorvidas pela mucosa sublingual dentro de 15 a 30 minutos, são fagocitados por células dendríticas locais ou células orais de Langerhans. O processo tem continuidade sendo responsável pela produção de IL-10 e TGF- $\beta$ levando a tolerância, também demarcada pela mudança de classe das imunoglobulinas e o aumento de títulos de IgE no início do procedimento, seguido de uma diminuição após meses do tratamento. Várias modificações induzem a tolerância nesse 
processo, tais como, supressão de APCs que mantêm a geração de células T efetoras; supressão direta da subpopulação Th2; modulação de linfócitos B, redução da produção de IgE específica para alérgenos e indução de IgG4 além de reduzir a atividade de outras células como eosinófilos, mastócitos e basófilos. Adicionalmente, SLIT também parece provocar a produção de IgA da mucosa, a qual pode contribuir para a tolerância (CHO et al., 2018).

\section{ViAS DE ADMINISTRAÇÃo DA AIT}

Como dito anteriormente, AIT pode ser administrada por via subcutânea (SCIT) ou sublingual (SLIT). Para ambas as formas de inoculação, são empregados um extrato bruto do alérgeno. Extratos brutos, contêm toda a gama de alérgenos principais que um paciente pode ser sensibilizado, o que acaba por aumentar a probabilidade de eficácia terapêutica em grande parte dos indivíduos. Vale dizer, ainda, que extratos brutos também contém numerosos constituintes não proteicos, tais como quitinas, $\beta$-glucanos e endotoxinas atuando sobre as células imunes inatas de forma pró-inflamatória (HESSE et al., 2018).

De acordo com Rajakulendran et al. (2018), os imunoterápicos são anticorpos monoclonais, anti-IL4 e anti-IgE, podendo ser classificados como alergoides ou sequências imunoestimuladoras. Os alergoides são vacinas contendo extrato de alérgeno modificado quimicamente por substâncias como glutaraldeído e formaldeído. Já as sequências imunoestimuladoras, segundo os autores, são sequências de oligodesoxinucleotideos de DNA contendo dinucleotídeos não metilados (CpG), reconhecidos pelo receptor Toll-Like 9 (TLR-9). Eles relatam ainda que alguns avanços na biologia molecular viabilizaram recombinantes específicos que se tornam eficazes tanto para SLIT como para SCIT, podendo variar de compostos fúngicos, moléculas parasitárias até ervas chinesas tradicionais.

Steveling-Klein (2016) explicou o protocolo de administração da imunoterapia. Segundo a autora, a forma mais comum de aplicação é a SCIT, envolvendo injeções repetidas preferencialmente na área dorsal superior do braço. Contudo, a preocupação sobre a gestão prática da SCIT, ou seja, a necessidade de supervisão do médico, deu espaço para o avanço da SLIT em gotas e comprimidos. A SLIT está disponível para aeroalergênicos como pólen de gramíneas, pólen de bétula e ácaro da poeira doméstica. Segundo a autora, as doses da SCIT dependem do tipo de alérgeno administrado, entretanto são recomendadas injeções semanais sobre 2 a 3 meses, seguidos por uma fase de manutenção com doses mais espaçadas ao longo 3 anos. Já na SLIT a primeira dose é administrada sob supervisão no ambiente clínico seguido de, geralmente, diariamente auto-administração ao longo, também, de 3 anos.

Apesar de a SCIT ser o tipo mais utilizado de terapia, este tipo de terapia também é motivo de redução da adesão ao tratamento, pois proporciona maiores riscos de reações adversas, principalmente a anafilaxia. Estratégias como a utilização de outras vias como as mucosas oral ou nasal por exemplo, ou a modificação da alergenicidade dos antígenos utilizados no processo da imunoterapia, têm sido aplicados para minimizar os riscos de efeitos adversos e contribuir no aumento da adesão ao tratamento, principalmente nas doenças alérgicas como asma e rinite, mais prevalente na população infantil que na adulta (MEDEIROS et al., 2009, p. 15).

Poucos estudos avaliaram a adesão da imunoterapia pelos pacientes. Seis estudos apontam que a taxa de adesão da SLIT variou de 75 a 95\%, sendo mais favorável que a SCIT, que teve variação de 33 a 89\% (KIOTSERIDIS et al., 2018). De acordo com Aboshady e Elghanam (2013), essa diferença de adesão se deve ao fato de que na SCIT, os pacientes necessitam ir ao consultorio para aplicação das doses injetáveis, necessitando de 30 ou mais consultas ao médico, enquanto que a SLIT oferece a possibilidade de administração domiciliar, reduzindo assim, a utilização dos recursos médicos.

\section{EFICÁCIA dos TIPOS DE AIT NAS DOENÇAS RESPIRATÓRIAS}

Steveling-Klein (2016) afirmam que o paciente ao optar pelo tratamento da imunoterapia deve receber 
todas informações verbais e escritas sobre a eficácia. A decisão sobre qual via de imunoterapia seguir depende, entre outras coisas, da avaliação de contraindicações e preferência do paciente. Segundo a autora algumas contraindicações devem ser levadas em conta, contudo, as mais importantes são doenças cardiovasculares, tratamento com beta bloqueadores (risco de anafilaxia), asma grave não controlada e gravidez.

Medeiros et al. (2009) elucidaram que a SLIT em alergia respiratória é extremamente eficaz e desprovida de efeitos adversos e promove um aumento da adesão ao tratamento quando comparada com a SCIT. Já Cho et al. (2018) debateram que existe eficácia tanto da SCIT quanto na SLIT no aspecto de redução dos escores de sintomas e medicação. No entanto, administração sublingual se torna uma opção viável quando há um problema de segurança, como reações sistêmicas graves, logo, a segurança da SLIT é significativamente maior.

Estudos conduzidos por Lourenço et al. (2007) utilizando imunoterapia específica injetável para inalantes, comprovam a eficácia da SCIT na melhora dos sintomas de pruridos e espirros em pacientes portadores de RA. Essa melhora também pôde ser observada em um estudo comparativo entre SLIT e SCIT, demonstrando que a SCIT era mais eficaz e agia mais precocemente em crianças asmáticas quando comparada à SLIT (ZAHNG et al., 2017).

Efeitos de transporte se mostraram persistentes por pelo menos 3 anos após a interrupção da SCIT e da SLIT, e benefícios clínicos contínuos podem ser observados após 12 anos da descontinuação da imunoterapia (ZHANG et al., 2012; SOHN, 2018)

Segundo Han e Rhee (2011), foi feita uma análise no ano de 2006 para verificar a eficácia da SLIT em 137 pacientes de 3 a 18 anos de idade com RA, o que mostrou uma redução significativa nos sintomas havendo melhora maior em 3 anos de tratamento com SLIT em comparação com um tratamento de 2 anos.

Silva (2008) declara que a "eficácia clínica perceptível da SCIT é alcançada nos primeiros 6 meses de tratamento e da SLIT pode demorar mais de 12 meses". Segundo ele, o efeito em longo prazo após a suspensão da imunoterapia está bem documentado para a SCIT que pode durar em torno de três a cinco anos. Saranz et al. (2010) demonstra que a SCIT teve efeito clínico benéfico entre 8 e 12 semanas de seu início, persistindo em até 7 anos após a suspensão do tratamento. Segundo o autor, é aconselhável seguir por três a cinco anos o tratamento para adquirir uma resposta clínica desejada, sendo que a decisão de interromper a imunoterapia deve ser avaliada individualmente para cada caso.

Zhang et al. (2017) descreve que o processo de SCIT envolve a inoculação de alérgenos como ácaros da poeira doméstica (HDM), pólen e pelos de animais através de administração subcutânea repetida com uma dose gradual.

Um estudo sobre a eficácia e segurança da SCIT em clínica de rotina em adultos coreanos acometidos com RA e sensibilizados com HDM foi apresentado por Sohn (2018). Segundo o autor, um grande estudo de coorte retrospectivo revisou 304 pacientes com RA tratados com SCIT visando o HDM sozinho ou com pólen por pelo menos 1 ano, e mostrou que o SCIT facilitou a remissão em 76,6\% dos pacientes com rinite alérgica por média 4,9 anos após o tratamento.

Tsabouri et al. (2017) analisaram 42 estudos de SCIT, onde foi possível observar que esse tipo de terapia reduz significativamente os sintomas tratamento de HDM e pólen, mas não era eficaz para pelos de animais ou misturas alergênicas. Os estudos mostraram ainda, que a SLIT é mais eficaz no chiado, enquanto que a SCIT pareceu mais eficaz na redução da tosse, além de ser mais eficaz no tratamento de pacientes com HDM e alergia o pólen e gramíneas, porém, ressaltam a necessidade de estudos adicionais para outros alérgenos.

Cho et al. (2018) em um estudo prospectivo randomizado envolvendo crianças de 5 a 17 anos, investigaram a SLIT com HDM na rinite alérgica. Dos 144 pacientes do estudo, 98 receberam HDM SLIT e a prevalência de asma persistente leve diminuiu significativamente no paciente tratado com SLIT com- 
parado com o grupo controle que tinha sido tratado apenas com terapia convencional. Concluíram que indivíduos com RA podem desenvolver uma asma alérgica, fenótipo mais comum da asma, que pode se apresentar em qualquer faixa etária. Entretanto, sabe-se que a asma alérgica se desenvolve em uma idade mais jovem do que a asma não alérgica, com idade média de início aos 15,8 anos, portanto, o HDM SLIT deve ser estabelecido antes dessa idade para evitar o surgimento da asma. De acordo com os autores, e resultados prévios de outros estudos envolvendo HDM SLIT, existe um prolongamento do efeito dessa terapia por até 7 ou 8 anos em indivíduos tratados durante 3 a 5 anos. Dessa forma, recomenta-se que a HDM SLIT seja aplicada por no mínimo 3 anos, para que sua eficácia a longo prazo seja alcançada e a eficiência clínica mantida após a descontinuação da imunoterapia.

Um estudo acompanhou indivíduos sensibilizados a HDM por 15 anos, sendo demonstrado que em pacientes que fizeram uso do SLIT por 3 anos tiveram benefícios por 7 anos, já pacientes com uso por 5 anos tiveram melhora por 8 anos, sugerindo que o tratamento ideal seria a administração da SLIT por 4 anos, pois induz uma melhora clínica duradoura, semelhante à do tratamento de 5 anos e maior do que a de uma SLIT de 3 anos (HAN; RHEE, 2011).

You et al. (2016) recrutaram 115 pacientes sensibilizados a HDM a fim de observar, em um tratamento de 2 anos, alguns aspectos na comparação dos dois tipos de imunoterapia: SLIT e SCIT. O primeiro aspecto notado foi a adesão ao tratamento, que, segundo os autores, foi maior na SCIT, num total de 51 indivíduos, 43 pacientes completaram o procedimento obtendo uma taxa de $84,31 \%$. Já na SLIT, eles constataram que de 64 indivíduos, 40 completaram o tratamento obtento uma taxa de 62,50\%. O segundo aspecto avaliado foram os escores de sintomas que não apresentaram diferenças. O último critério julgado pelos autores foi a segurança de ambos os procedimentos, sendo notado que algumas reações adversas na SCIT e nenhuma reação na SLIT.

Nunes (2011) da Sociedade Portuguesa de Alergologia e Imunologia Clínica abordaram a relação de custos do tratamento com SLIT e SCIT na Europa e destacaram alguns pontos relevantes nos benefícios desse tipo de terapia. Para eles, as doenças como rinite e asma de etiologia atópica possuem mortalidade elevada e alteram profundamente a qualidade de vida dos doentes, sendo assim a imunoterapia poderia trazer grandes benefícios mesmo se levar em conta os custos do tratamento. Os autores levantaram ainda que se estima cerca de 340 euros anual o custo médio da rinite alérgica por indivíduo e que o custo anual na prevenção, tratamento e reabilitação de um asmático seja em média de 915 euros. Em relação à imunoterapia, a SCIT possui um custo anual de 200 euros contra 400 euros da SLIT, se usados em tratamento contínuo segundo as recomendações atuais.

AIT continua sendo o único tratamento que modifica as causas subjacentes de doenças alérgicas, resultando remissão a longo prazo (STEVELING-KLEIN, 2016). Muitas pesquisas atuais têm buscado afirmar o melhor método de administração, além de confirmação da eficácia e novas misturas específicas de alérgenos para aumentar o número de alergias desse tipo de tratamento.

\section{CONSIDERAÇÕES FINAIS}

Esta Revisão Bibliográfica permite concluir que a partir da compreensão mecanismos de hipersensibilidade do tipo 1 é possível entender o princípio ativo das novas perspectivas de tratamentos para alergias das vias aéreas. A imunoterapia específica com alérgenos é um potente tratamento para rinite alérgica e asma que envolve não apenas um desvio de células Th2 para Th1, mas também a participação de células $\mathrm{T}$ e $\mathrm{B}$ regulatórias e mecanismo de resposta precoces, intermediários e tardios.

Os autores descrevem que esse tipo de imunoterapia envolve a administração de alérgenos específicos e surgiu, diferentemente da farmacoterapia pré-existente, com o intuito de induzir a tolerância imunológica devido ao fato de modificar a resposta a alérgenos. Sendo assim, a AIT tem a capacidade de alterar o decurso natural das doenças, melhorando a qualidade de vida, evitando a progressão da RA e prevenindo 
o início da asma.

Vários estudos têm demonstrado que a rinite alérgica (RA) é um problema mundial de saúde que tem apresentado elevada incidência e prevalência, podendo predizer a progressão para asma. Logo, tem se recomendado que a Imunoterapia se inicie na idade inferior a 15,8 anos, para evitar de maneira mais eficaz a evolução da RA. Essa terapia pode ser por via subcutânea ou por mucosas oral e nasal, sendo que a sublingual é a mais recente forma do tratamento e a via que tem mostrado mais fatores positivos.

Ainda há controversas sobre qual o método é o mais eficaz, existem inúmeros fatores que podem ser levados em conta durante a comparação como, por exemplo, a redução dos sintomas e a adesão ao tratamento. Alguns estudos feitos com indivíduos alérgicos identificaram que enquanto o chiado respondeu melhor ao SLIT, o SCIT pareceu ser mais eficaz na redução da tosse. Já outros estudos salientam que em termos de redução dos sintomas elas se igualam, mas a SLIT tem apresentado maior adesão.

Portanto, é de extrema relevancia conhecer, os principais mecanismos nos quais a imunoterapia atua no tratamento das hipersensibilidades do tipo I, especialmente em doenças de vias aéreas como a RA e a asma, permitindo uma melhora na qualidade de vida das pessoas ou prevenindo o avanço dessas doenças.

\section{REFERÊNCIAS}

ABOSHADY, O.; ELGHANAM, K. Sublingual Immunotherapy in Allergic Rhinitis: Efficacy, Safety, Adherence and Guidelines. Clinical and Experimental Otorhinolaryngology, Menoufia, v. 7, n. 4, p. 241-244, Abr. 2013. Disponível em: < https://www.researchgate.net/publication/263013122_Sublingual_Immunotherapy_in_Allergic_Rhinitis_Efficacy_Safety_Adherence_and_Guidelines $>$ Acesso em: 08 mai. 2018

BERINGS, M.; KARAASLAN C.; ALTUNBULAKLI C.; GEVAERT P.; AKDIS M.; BACHERT C.; AKDIS C.A. Advances and highlights in allergen immunotherapy: On the way to sustained clinical and immunologic tolerance. J Allergy Clin Immunol. Ghent, v. 140, n. 5, p. 1250-1267, Nov. 2017. Disponível em:< https://www.ncbi.nlm.nih.gov/pubmed/28941667> Acesso em: 26 mai. 2018.

CHIRUMBOLO, S.; BJØRKLUND G.; SBOARINA A.; VELLA, A. The role of basophils as innate immune regulatory cells in allergy and immunotherapy. Human Vaccines \& Immunotherapeutics, Verona, v. 14, n. 4, p. 815-831, Dec. 2017. Disponível em: < https://www.ncbi.nlm.nih.gov/pubmed/29257936 > Acesso em: 10 abr. 2018.

CHO, S. W.; HAN D.H.; KIM J.W.; KIM D.Y.; RHEE C.S. House dust mite sublingual immunotherapy in allergic rhinitis. Future Medicine Ltd, Seoul, v. 10, n. 5, p. 01-12, Mar. 2018. Disponível em: < https:// www.ncbi.nlm.nih.gov/pubmed/29562802> Acesso em: 10 abr. 2018.

ELENIUS, V;; JARTTI, T. Vaccines: Could asthma in young children be a preventable disease? Pedriatric Allergy and Immunology, Turku, v. 27, n. 7, p. 682-686, Nov. 2016. Disponível em:< https://www.ncbi. nlm.nih.gov/pubmed/27171908> Acesso em: 05 abr. 2018.

FERREIRA, M. B. Imunoterapia com ácaros. Rev Port Imunoalergologia, Lisboa, v. 23, n. 2, p. 7987, Jun. 2015. Disponível em: $<\mathrm{http}$ //www.scielo.mec.pt/scielo.php?script=sci_arttext\&pid=S087197212015000200003\&lng=pt\&nrm=iso $>$. Acesso em: 26 abr. 2018.

HANCI, D.; ŞAHIN, E., MULUK, N.B., CINGI, C. Immunotherapy in all aspects. European Archives 
Faccio et al.

of Oto-Rhino-Laryngology, Istanbul, v. 273, n. 6, p. 1347-1355, Jun. 2016. Disponível em:< https://www. ncbi.nlm.nih.gov/pubmed/25673026 > Acesso em: 10 abr. 2018.

HAN, D.H.; RHEE, C.S. Sublingual immunotherapy in allergic rhinitis. Asia Pac Allergy, Seongnam, v. 1, n. 3, p. 123-129, Oct. 2011. Disponível em:<https://www.ncbi.nlm.nih.gov/pmc/articles/PMC3206241> Acesso em: 08 mai. 2018.

HESSE, L. VAN IEPEREN, N.; HABRAKEN, C.; PETERSEN, A.H.; KORN, S.; SMILDA, T.; GOEDEWAAGEN, B.; RUITERS, M.H.; VAN DER GRAAF, A.C.; NAWIJN, M.C. Subcutaneous immunotherapy with purified Der $\mathrm{p} 1$ and 2 suppresses type- 2 immunity in a murine asthma model. Allergy European Journal of allergy and Clinical Immunology, Groningen, v. 73, n. 4, p. 862-874, Jan. 2018. Disponível em:< https://www.ncbi.nlm.nih.gov/pubmed/29318623> Acesso em: 26 abr. 2018.

IBIAPINA, C. C.; SARINHO, E.S.C; CAMARGOS, P.A.M.C.; ANDRADE, C.R.; CRUZ -FILHO, A.A.S. Rinite alérgica: aspectos epidemiológicos, diagnósticos e terapêuticos. J. bras. pneumol., Belo Horizonte, v. 34, n. 4, p. 230-240, Abr. 2008. Disponível em: <http://www.scielo.br/scielo.php?script=sci_arttext\&pid=S1806-37132008000400008\&lng=en\&nrm=iso > Acesso em: 26 abr. 2018.

KIOTSERIDIS, H.; ARVIDSSON, P. BACKER, V. BRAENDHOLT, V.; TUNSÄTER, A. Adherence and quality of life in adults and children during 3-years of SLIT treatment with Grazax-a real life study. NPJ Primary Care Respiratory Medicine, Lund, v. 28, n. 4, p. 8, Feb. 2018. Disponível em: <https:// www.nature.com/articles/s41533-018-0072-z $\geq$ Acesso em: 25 abr. 2018.

KUMAR, Y.; BHATIA, A. Immunopathogenesis of allergic disorders: current concepts. Expert Reviews Ltd, Chandigarh, v. 9, n. 3, p. 211-226, Mar. 2013. Disponível em:< https://www.ncbi.nlm.nih.gov/pubmed/23445196> Acesso em: 20 abr. 2018.

LOURENÇO, E. A.; PANDINI, F.E.; SANCHEZ, A.L.; SILVA, A.R. Efeitos da imunoterapia dessensibilizante específica no prurido e espirros da rinite alérgica. Perspectivas Médicas, Jundiaí, v. 9, n. 1, p. 5-9, mai. 2008. Disponível em: < http://www.redalyc.org/html/2432/243217737002> Acesso em: 09 mai. 2018.

MORJARIA, J.B.; CARUSO, M.; EMMA, R.; RUSSO, C.; POLOSA, R. Treatment of Allergic Rhinitis as a Strategy for Preventing Asthma. Current allergy and asthma reports, Harefiel, v. 18, n. 23, p. 02-13, Mar. 2018. Disponível em: < https://www.ncbi.nlm.nih.gov/pubmed/29574527> Acesso em: 02 mai. 2018.

MEDEIROS-JÚNIOR, M.M.; LYRA, A.P.; SANTOS, H.B.; MENDES, C.M. ALMEIDA, K.C.; SILVA, D.A.; TAKETOMI, E.A. Eficácia clínica da imunoterapia nasal comparada com imunoterapia sublingual em pacientes com rinite alérgica. Revista oficial da Associação Brasileira de Alergia e Imunologia, Uberlândia, v. 32, n. 1, p. 13-17, Jan. 2009. Disponível em:< http://aaai-asbai.org.br/detalhe_artigo. asp?id=174> Acesso em: 08 mai. 2018.

MURPHY, K.; TRAVERS, P.; WALPORT, M. Imunobiologia de Janeway. 7 ed. Porto Alegre: Artmed, 2010, p. 553-570.

NUNES, C.; PEDRO E.; SANTOS, A.S.; LOPES, A.; COSTA, A.C.; TOD0-BOM, A.; GASPAR, A.; LOU- 
REIRO, C.; CHIEIRA, C.; PEREIRA, C.; GOMES, E.; BENSO, L.; CHIEIRA, L.; MORAIS-ALMEIDA, M.; ALVES, R.R.. Normas de orientação em Imunoterapia Específica. Revista portuguesa de imunoalergologia, Lisboa v. 19, n. 4, p. 199-213, Jul. 2011. Disponível em: <https://www.spaic.pt/client_files/ rpia_artigos/normas-de-orientacao-em-imunoterapia-especifica.pdf> Acesso em: 10 mai. 2018.

PASTORINO, A. C. Revisão sobre a eficácia e segurança dos anti-histamínicos de primeira e segunda geração. Revista oficial da Associação Brasileira de Alergia e Imunologia, São Paulo, v. 33, n. 3, p. 8890, ago. 2010. Disponível em: <http://aaai-asbai.org.br/detalhe_artigo.asp?id=110> Acesso em: 26 mai. 2018.

PEREIRA, V. A. R.; AUN, W. C. T.; MELLO, J. F. Mecanismos da imunoterapia alérgeno-específica. Revista oficial da Associação Brasileira de Alergia e Imunologia, São Paulo, v. 1, n. 3, p. 257-262, set. 2017. Disponível em: <http://aaai-asbai.org.br/detalhe_artigo.asp?id=789> Acesso em: 11 abr. 2018.

PFAAR, O.; BONINI, S.; CARDONA, V.; DEMOLY, P.; JAKOB, T.; JUTEL, M.; KLEINE-TEBBE, J.; KLIMEK, L.; KLYSNER, S; KOPP, M.V.; KUNA, P.; LARCHÉ, M.; MURARO, A.; SCHMIDT-WEBER, C.B.; SHAMJI, M.H.; SIMONSEN, K.; SOMOZA, C.; VALOVIRTA, E.; ZIEGLMAYER, P.; ZUBERBIER, T.; WAHN, U.; FASIT group.et al. Perspectives in allergen immunotherapy: 2017 and beyond. Allergy, Mannheim, v. 73, n. 104, p. 05-23, Jan. 2018. Disponível em:< https://www.ncbi.nlm.nih.gov/ pubmed/29171712> Acesso em: 26 mai. 2018.

RAJAKULENDRAN, M.; THAM, E.H., SOH, J.Y., VAN BEVER, H.P. Novel strategies in immunotherapy for allergic diseases. Asia Pasifc Allerg, Singapore, v. 8, n. 2, p. 1-18, Apr. 2018. Disponível em: < https://www.ncbi.nlm.nih.gov/pmc/articles/PMC5931921/> Acesso em: 26 mai. 2018.

RICE, J. L.; DIETTE, G.B.; SUAREZ-CUERVO, C.; BRIGHAM, E.P.; LIN, S.Y.; RAMANATHAN-JR, M.; ROBINSON, K.A.; AZAR, A. Allergen-Specific Immunotherapy in the Treatment of Pediatric Asthma: A Systematic Review. Pediatrics, Baltimor, v. 141, n. 5, p. 02-08, Mar. 2018. Disponível em: < https:// www.ncbi.nlm.nih.gov/pubmed/29572287> Acesso em: 15 mai. 2018.

SARANZ, R. J.; LOZANO, A.; CÁCERES, M.E. ARNOLT, R.G.; MÁSPERO, J.F.; BAZZOLA, C.M.; NEFFEN, H.E.; CROCE, V.H.; GUALTIERI, O.; PROCOPIO, N. Inmunoterapia com alergenos para la prevención y el tratimiento de las enfermidades alérgicas respiratórias de la infnacia. Arco. Argent. Pediatr., Buenos Aires, v. 108, n. 3, p. 258-265, Jun. 2010. Disponível em <http://www.scielo.org.ar/scielo. php?script=sci_arttext\&pid=S0325-00752010000300020\&lng=es\&nrm=iso $>$ Acesso em: 06 mai. 2018.

SATITSUKSANOA, P.; GLOBINSKA, A.; JANSEN, K.; VAN DER VEEN, W.; AKDIS, M. Modified Allergens for Immunotherapy. Current allergy and asthma reports, Davos, v. 18, n. 9, p. 15-18, Feb. 2018. Disponível em:< https://www.ncbi.nlm.nih.gov/pubmed/29450658> Acesso em: 11 abr. 2018.

SILVA, E. C. F. S. Imunoterapia específica em alergia respiratória. Revista do Hospital Universitário Pedro Ernesto, Rio de Janeiro, v. 7, n. 2, p. 84-91, dez. 2008. Disponível em:< http://revista.hupe.uerj.br/ detalhe_artigo.asp?id=206> Acesso em: 09 mai. 2018.

SOHN M.H. Efficacy and Safety of Subcutaneous Allergen Immunotherapy for Allergic Rhinitis. Allergy Asthma Immunology Research, Seoul, v. 10, n. 1, p. 1-3, Jan. 2018. Disponível em:< https://www.ncbi. 
nlm.nih.gov/pubmed/29178670> Acesso em: 10 abr. 2018.

STEVELING-KLEIN, E. H. Allergen-specific immunotherapy. European Medical Journal, Basel, v. 1, n. 4, p. 78-87, Aug. 2016. Disponível em: < https://pdfs.semanticscholar.org/9469/2821f537afa84a059f195ae44d5082a03704.pdf> Acesso em: 10 mai. 2018.

THANGAM E.B.; JEMIMA, E.A.; SINGH, H.; BAIG, M.S.; KHAN, M.; MATHIAS, C.B.; CHURCH, M. K.; SALUJA, R. The Role of Histamine and Histamine Receptors in Mast Cell-Mediated Allergy and Inflammation: The Hunt for New Therapeutic Targets. Frontiers in Immunology. 2018;9:1873. doi:10.3389/ fimmu.2018.01873.

TSABOURI, S.; MAVROUDI, A.; FEKETEA, G.; GUIBAS, G.V. Subcutaneous and sublingual immunotherapy in allergic asthma in children. Front. Pediatr. v. 5, n. 82, p. 1-21, Apr. 2017. Disponível em: < https://www.ncbi.nlm.nih.gov/pubmed/28484690\#> Acesso em: 10 mai. 2018.

VEEN, W. V.; WIRTZ, O.F.; GLOBINSKA, A.; AKDIS, M. Novel mechanisms in immune tolerance to allergens during natural allergen exposure and allergen-specific immunotherapy. Curr Opin Immunol. Davos, v. 48, n. 1, p. 74-81, Oct. 2017. Disponível em:< https://www.ncbi.nlm.nih.gov/pubmed/28888176> Acesso em: 26 mai. 2018.

VIRTANEN, T. Immunotherapy for pet allergies. Human Vaccines \& Immunotherapeutics, Kuopio, v. 14, n. 4, p. 807-814, Nov. 2017. Disponível em: < https://www.ncbi.nlm.nih.gov/pubmed/29182437> Acesso em: 10 abr. 2018.

YOU, S.H.; QIN, X.Y.; XU, C.; QIU, X.; LUAN, Z.L.; JÁ, H.X.; WANG, H.T. Comparison study of subcutaneous immunotherapy and sublingual immunotherapy in patients with allergic rhinitis. Lin Chung Er Bi Yan Hou Tou Jing Wai Ke Za Zhi. Beijing, v. 30, n. 9, p. 689-693. May. 2016. Disponível em:< https://www.ncbi.nlm.nih.gov/pubmed/29771014> Acesso em: 26 mai. 2018.

ZHANG, W.; CHUNRONG, L.; SAMPATH, V.; NADEAU, K.. Impact of allergen immunotherapy in allergic asthma. Future Medicine Ltd, Stanford, v. 10, n. 5, p. 21-37, Mar. 2018. Disponível em:< https:// www.futuremedicine.com/doi/abs/10.2217/imt-2017-0138> Acesso em: 10 abr. 2018. 